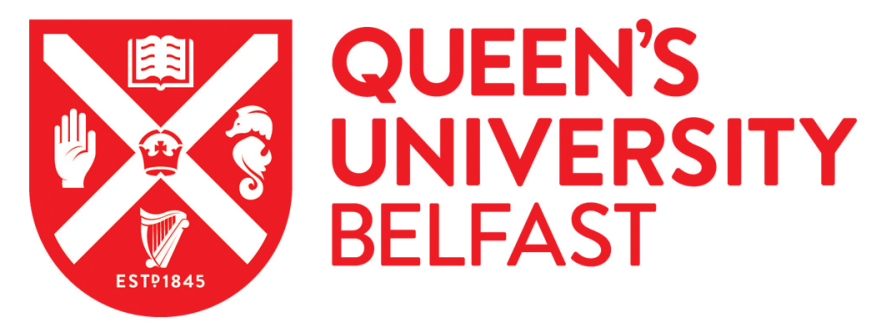

\title{
Fine mapping of genes determining extrafusal fiber properties in murine soleus muscle
}

Carroll, A., Cheng, R., Collie-Duguid, E., Meharg, C., Scholz, M., Fiering, S., Fields, J., Palmer, A., \& Lionikas, A. (2017). Fine mapping of genes determining extrafusal fiber properties in murine soleus muscle.

PHYSIOLOGICAL GENOMICS, 49(3), 141-150. https://doi.org/10.1152/physiolgenomics.00092.2016

\author{
Published in: \\ PHYSIOLOGICAL GENOMICS
}

\section{Document Version:}

Peer reviewed version

Queen's University Belfast - Research Portal:

Link to publication record in Queen's University Belfast Research Portal

Publisher rights

(C) 2016 The American Physiological Society

This work is made available online in accordance with the publisher's policies. Please refer to any applicable terms of use of the publisher.

\section{General rights}

Copyright for the publications made accessible via the Queen's University Belfast Research Portal is retained by the author(s) and / or other copyright owners and it is a condition of accessing these publications that users recognise and abide by the legal requirements associated with these rights.

Take down policy

The Research Portal is Queen's institutional repository that provides access to Queen's research output. Every effort has been made to ensure that content in the Research Portal does not infringe any person's rights, or applicable UK laws. If you discover content in the Research Portal that you believe breaches copyright or violates any law, please contact openaccess@qub.ac.uk. 
1 Fine mapping of genes determining extrafusal fiber properties in murine soleus

2 muscle

3 Carroll $\mathrm{AM}^{1,2}$, Cheng $\mathrm{R}^{3}$, Collie-Duguid $\mathrm{ESR}^{1,4}$, Meharg $\mathrm{C}^{5}$, Scholz $\mathrm{ME}^{1}$, Fiering $\mathrm{S}^{6}$, Fields $4 \quad \mathrm{JL}^{6}$, Palmer $\mathrm{AA}^{7}$, Lionikas $\mathrm{A}^{1}$.

5

6 Affiliation:

$7{ }^{1}$ School of Medicine, Medical Sciences and Nutrition, University of Aberdeen, Foresterhill 8 Aberdeen, AB25 2ZD, UK

$9 \quad{ }^{2}$ The New Zealand Institute for Plant \& Food Research Limited, Batchelar Road, Private Bag 1011600 , Palmerston North 4442, New Zealand

$11{ }^{3}$ Research School of Biology, The Australian National University, 134 Linnaeus Way, Acton, 12 ACT 2601, Australia

$13{ }^{4}$ Centre for Genome Enabled Biology and Medicine, University of Aberdeen, Old Aberdeen, 14 Aberdeen, AB24 3RY, UK

$15{ }^{5}$ Institute for Global Food Security, Queen's University Belfast, 18-30 Malone Road, Belfast, 16 BT9 5BN, UK

$17{ }^{6}$ Department of Microbiology/immunology, Geisel School of Medicine at Dartmouth, 18 Hanover, NH 03755, USA

$19{ }^{7}$ Department of Psychiatry, University of California San Diego, 9500 Gilman Drive, Mail Code 0667, BRF2 3A24, La Jolla, CA 92093, USA 


\section{Abstract}

28 Introduction. Muscle fiber cross-sectional area (CSA) and proportion of different fiber types

29 are important determinants of muscle function and overall metabolism. Genetic variation

30 plays a substantial role in phenotypic variation of these traits, however, the underlying genes

31 remain poorly understood.

32 Aims. This study aimed to map quantitative trait loci (QTL) affecting differences in soleus

33 muscle fiber traits between the LG/J and SM/J mouse strains.

34 Methods. Fiber number, CSA, and proportion of oxidative type I fibers were assessed in the 35 soleus of 334 genotyped female and male mice of the $F_{34}$ generation of advanced intercross lines (AIL) derived from the $L G / J$ and SM/J strains. To increase the QTL detection power,

37 these data were combined with 94 soleus samples from the $F_{2}$ intercross of the same

38 strains. Transcriptome of the soleus muscle of $L G / J$ and $S M / J$ females was analysed using

39 microarray.

40 Results. Genome-wide association analysis mapped 4 QTL (genome-wide $p<0.05$ )

41 affecting the properties of muscle fibers to Chromosome 2, 3, 4 and 11. A 1.5-LOD QTL

42 support interval ranged between 2.36 Mb and 4.67 Mb. Based on the genomic sequence

43 information, functional and transcriptome data, candidate genes were identified for each of

44 these QTL.

45 Conclusion. Combination of analyses in $F_{2}$ and $F_{34}$ AIL populations with transcriptome and 46 genomic sequence data in the parental strains is an effective strategy for refining QTL and 47 nomination of the candidate genes.

49 Key words: skeletal muscle, muscle fiber types, genetic variation 


\section{$51 \quad$ Introduction}

52 Skeletal muscle plays a broad range of biological functions including locomotion,

53 thermoregulation, respiration, postural support, protection of bones and viscera; as well as

54 serving as a source of amino acids in times of starvation or disease. Muscle tissue in

55 livestock also provides an essential source of dietary proteins. In humans, there is more

56 than a 2-fold difference in muscle mass between individuals of similar age and same sex (3,

57 33). This is the outcome of variability in the number of muscle fibers and their size (51).

58 These differences are of clinical relevance. Variability in muscle mass significantly impacts energy expenditure (58), influencing preponderance to obesity. In addition, individuals with lower muscle mass may be more vulnerable to impairment of these vital functions due to aging and/or disease related muscle loss. It has recently been reported that there is a positive association between muscle mass and longevity in older adults (66).

Human skeletal muscles are mainly comprised of a mixture of type I, IIA and IIX muscle fibers (62). The number of fibers, their size and varying proportions of the fiber types affect morphological and functional properties of the muscle (6). A larger diameter of the fibers and higher number of fibers typically leads to augmented muscular strength and power (25, 28). The proportion of type I muscle fibers is a factor determining success in endurance sporting events $(15,18)$ and overall metabolism in humans $(24,29,44,74)$. In livestock, proportion of oxidative type I fibers is associated with meat quality (65).

In humans, genetic factors account for around half of the variation in strength $(19,24,74)$ and the upper limit heritability is even greater (over 0.9 ) for muscle mass (26). Heritability estimates of proportion of type I fibers is also high, ranging between 0.4 and 0.9 , indicating that genetic factors play an important role in determining muscle fiber properties $(37,63)$.

76 Effects of genetic factors on muscle fibers have also been demonstrated in mouse (20, 22, 
77 59), cattle (68), sheep $(10,38)$ and pig (71). However, the specific genes underlying these

78 effects remain largely elusive.

80 Attempts at mapping the polygenic architecture of muscle fiber properties in mouse (11), pig

$81(17,43,52,55,77)$, cattle (1) and carp (80) have been made. A number of QTL have been

82 identified in these studies. However, the resolution achieved in the $F_{2}$ population is not

83 adequate for reliable nomination of the candidate genes in the majority of the QTLs of

84 polygenic traits. The mouse soleus muscle (primarily consists of type I and IIA fiber types),

85 closely resembles the fiber type composition of human skeletal muscles (primarily comprised

86 of type I, IIA and IIX fiber types), and is therefore a particularly interesting experimental

87 model. In our previous study, we mapped soleus muscle fiber traits in an $\mathrm{F}_{2}$ intercross

88 between the LG/J and SM/J laboratory mouse strains (11). These strains differ in a number

89 of muscular phenotypes, with the LG/J strain displaying a greater proportion of type I fibers,

90 and a greater cross-sectional area (CSA) of type I and IIA muscle fibers. We identified in

91 that study three significant QTLs contributing to the difference in the CSA of muscle fibers

92 between LG/J and SM/J strains (11). Regions of conserved synteny from the identified loci

93 were also implicated in fiber phenotypes in pig supporting the importance of these genomic

94 regions in determining muscle fiber properties. However, the exact genes underlying their

95 effects remain to be determined.

Integration of advanced study populations, high throughput gene expression technology and

98 increasing availability of knockout models aid identification of the causative genes.

99 Nomination of the genes underlying QTL effects can be facilitated by improving the mapping

100 resolution, and by utilising genomic sequence and transcriptome information. Advanced

101 intercross lines (AIL) have been proposed as a powerful population for mapping QTLs (16).

102 It has been demonstrated recently that a joint $F_{2}$ and AIL analysis can combine the 
103 advantages of both mapping populations by increasing the power to detect QTLs and

104 achieving a higher mapping resolution of various traits in mice $(13,47)$. Additionally, testing

105 for differences in specific gene expression has led to several nominations of quantitative trait

106 genes $(30,35)$. For validation of such candidate genes, phenotypic effects of relevant

107 alleles can be examined in experimental populations where these alleles segregate albeit on

108 a different genetic background. In addition, available knockout models offers particularly

109 attractive option for validation experiments.

110 In the present study we aimed to fine-map QTL and nominate candidate genes affecting the

111 CSA and proportion of oxidative type I fibers in the soleus muscle in a combined analysis of

$112 \mathrm{~F}_{2}$ and $\mathrm{F}_{34}$ AlL mice, and by cross referencing QTL data with soleus transcriptome profiles in

113 the parental strains. Further filtering of the emerged candidates was carried out in an

114 independent AlL and a knockout model. 
118 This study was carried out on soleus muscles dissected from females and males of the $F_{34}$ advanced intercross lines (AIL) of the $\mathrm{LG} / \mathrm{J}$ and $\mathrm{SM} / \mathrm{J}$ inbred strains. Animals were maintained as previously described (13) and sacrificed at $94 \pm 4$ days. All procedures were approved by the Institutional Animal Care and Use Committee of the University of Chicago.

122 Soleus muscle samples from $\mathrm{F}_{34}$ AlL mice described in our previous study (47) were subjected to histological analyses. The final sample size used in the present study was 334 $F_{34}$ mice, 142 females and 192 males, after discarding samples of poor tissue quality. A set of 94 F2 samples (38 females and 56 males) described in our previous study (11) was also used in order to increase the QTL detection power.

In addition, we also analysed soleus muscle samples for two hypothesis driven studies aimed at testing the effects of identified candidate genes on percentage of oxidative, type I fibers. First, we examined solei samples from the Chd6 ATPase knockout $(n=6)$, heterozygous $(n=4)$ and wild type $(n=4)$ females. The generation of the Chd6 mutant mice has been previously reported (40). Briefly, the genetic manipulation generated an allele with the ATPase domain of Chd6 (exon 12) flanked by loxP sites so that the action of Cre recombinase would delete this domain. The mice were mated to a germline Cre-expressing strain (Jackson lab strain 003465) to delete both exon 12 and the neomycin resistance marker used for the targeting. Subsequently breeding generated the Chd6 ATPase knockout mice utilized in the present study. Second, solei of the advanced intercross mice (generations $\left.F_{9}-F_{12}\right)$, all homozygous carries of the C57BL/6J $(n=22)$ or DBA/2J $(n=23)$ alleles at the region harbouring the Alad gene were selected from the tissue bank of our previous study (9).

\section{Phenotype assessment}


141 The soleus muscles were frozen in isopentane cooled in liquid nitrogen. Transverse

142 sections from the belly of the muscle were cut at a thickness of $10 \mu \mathrm{m}$ with a cryotome

143 (Leica CM1850UV) at $-20^{\circ} \mathrm{C}$. The muscle sections were subjected to ATPase staining (acid

144 pre-incubation, $\mathrm{pH} 4.47$ ) to distinguish between fiber types (8). Microscopic images of

145 stained sections were taken at $x 5$ and $\times 20$ magnification.

146 The following phenotypes were assessed: muscle fiber number (type I and IIA) and percent 147 of type I muscle fibers, cross-sectional area (CSA) of type I and type IIA fibers (Figure 1).

148 Muscle fiber traits were manually analysed using ImageJ software (NIH-version 1.43). 25

149 measurements of each fiber type were taken using the freehand selection tool at x20

150 magnification to obtain a value representing the mean CSA of type I or type IIA fibers for that

151 muscle. This was deemed as a representative sample by empirical testing as described

152 previously (11). Total number of type I and type IIA muscle fibers were counted using the

153 Image cell counter plugin on $\mathrm{x} 5$ magnification images. As all fibers in mouse soleus pass

154 through the belly of the muscle (69), this method provides an accurate estimate of the

155 number of fibers constituting the muscle. Total number of type I fibers and total number of

156 type IIA fibers were counted, permitting derivation of percentage of type I fibers. Over the

157 course of the study $\sim 200,000$ muscle fibers were counted and $\sim 6,700$ fibers measured for

158 CSA.

Statistical analyses

160 The GraphPad Prism version 5.0 statistical package was used (GraphPad software, La Jolla,

161 CA). Data are presented as mean \pm SD, unless otherwise stated. The CSA of type I and

162 type IIA fibers were analysed using a two-way (sex and fiber type) paired-measures (type I

163 and type IIA fibers) ANOVA.

164 Genotyping and QTL mapping

165 Mice were genotyped using a custom designed SNP array that included 4,610 polymorphic

166 SNPs that were approximately evenly distributed across the genome, as described 
167 previously (13). The genome-wide association analysis was performed in the combined

168 population of the $F_{34}$ and recently published $F_{2}$ intercrosses (11) using the $R$ package

169 QTLRel (12). This software accounted for the complex relationships (e.g., sibling, half-

170 sibling, cousins) among the $F_{34}$ mice by using a mixed model, as previously described (12,

171 13). Due to the sex differences in muscle mass in these mice (47), and the discovery of sex

172 specific QTL in other studies $(45,46)$, we included sex as an additive and interacting

173 covariate. Threshold of significance was estimated by 1000 permutations (14). We defined

174 the support interval for each QTL as the 1.5-LOD drop off on either side of the peak marker.

175 This interval was expressed in physical map position (Mb) by using the nearest genotyped

176 SNP that flanked the support interval, based on the mouse genome build GRCm38.p3.

177

\section{$\underline{\text { Transcriptome analysis }}$}

Soleus muscle tissues from 92-day old LG/J and SM/J females ( $n=3$ of each strain) were used. RNA was isolated using TRIzol (Invitrogen Life Technologies, Carlsbad, CA) followed by purification and DNase digestion using RNeasy minikits (Qiagen, Venlo, Netherlands) according to the manufacturer's instructions. Quantification of total RNA was performed on a NanoDrop spectrophotometer (Thermo Scientific) and quality tested on an Agilent Tapestation with R6K Screentapes (RIN $\geq 7.3$ ). Generation of sense strand cDNA from purified total RNA (Ambion ${ }^{\circledR}$ WT expression kit, Ambion, Austin, Texas) followed by fragmentation and labelling (GeneChip WT labelling kit, Affymetrix, Santa Clara, CA) were performed according to the manufacturer's instructions. Hybridisation, washing, staining and scanning of microarrays were carried out on Affymetrix Mouse Gene 2.0 ST microarrays according to the manufacturer's standard protocols using a GeneChip Fluidics station 450 and GCS3000 scanner (Affymetrix ${ }^{\circledR}$, Santa Clara, CA). Microarray data are available in the ArrayExpress database (www.ebi.ac.uk/arrayexpress) under accession number E-MTAB5290. 
193 Data pre-processing and quality control analysis was performed using Affymetrix®

194 Genechip® Expression Console v1.2. Probe cell intensity data on the Mouse Gene 2.0 ST array (CEL files) were processed using the RMA16 algorithm (Affymetrix, Santa Clara, CA, USA) which fits a robust linear model at probe level by employing background correction, quantile normalisation of log2 transformed data and summarisation to probe level data (CHP files, 41,345 probe sets).

Data was analysed for differentially expressed genes in Partek $®$ Genomics Suite ${ }^{\circledR}$ version 6.6, build 6.15.0730 (Partek Inc., St Louis, MO) using a Mus musculus build mm10 annotation file for Mouse Gene 2.0 ST microarrays (MoGene-2_0-st-v1.na35.mm10). CEL files (Expression Console v 1.2, Affymetrix, Santa Clara, CA) were imported to Partek Genomics Suite v 6.6 and processed using RMA normalisation with background correction of log2 transformed data and probe set summarisation by median polish. Differential expression analysis between the $L G / J$ and $S M / J$ strains of all genes $(n=41,345$ transcript clusters) was determined by 1-way ANOVA with Storey's FDR, and q-value $\leq 0.05$ considered significant $(n=819$ genes differentially expressed $\geq 1.2$ fold; see Supplementary Table 1).

To assess transcription of positional candidate genes in each strain, a hypothesis driven analysis of differential gene expression was performed between the LG/J and SM/J strains on all genes mapping to the support interval defined for each QTL in the GWAS described above. Using Partek Genomics Suite v.6.6, a total of 159 genes that were represented on the mouse Gene 2.0ST microarray, were identified in Mus musculus genome build GRCm38, mm10 within mapping co-ordinates Chr2:158908559-162608559 (26 genes), Chr3:33308451-35708451 (15 genes), Chr4:57605946-62913639 (77 genes) or Chr 11:27900000-31500000 (41 genes). 1-way ANOVA identified differentially expressed genes between the $L G / J$ and $S M / J$ strains $(P<0.05)$. Fold change was calculated using the geometric mean of samples in each group. 
221 Nomination of the candidate genes was based on the following three criteria. First, we

222 scrutinized polymorphisms in positional candidates between the $\mathrm{LG} / \mathrm{J}$ and $\mathrm{SM} / \mathrm{J}$ strains. The

223 emphasis was on the indels and SNPs that would affect the coding sequence and lead to

224 changes in amino acids. To assess whether amino acid substitution would influence the

225 function of a protein, evolutionary conservation at the site of substitution and properties of

226 substituted amino acids were considered using three different bioinformatics tools as

227 described by Nikolskiy and colleagues (56). Second, we examined expression of positional

228 candidates across a panel of over ninety mouse tissues and cell types available in BioGPS

229 GeneAtlas MOE430, gcrma dataset (79). This analysis permits a quantitative comparison of

230 transcript abundance of a gene between tissues. We considered that an abundant

231 expression in skeletal muscle lineage, i.e. muscle tissue and/or $\mathrm{C} 2 \mathrm{C} 12$ myogenic cell line,

232 implies functional and/or structural relevance of a gene in this tissue. Third, we compared

233 gene expression levels in the soleus muscle between the two strains as described in the

234 previous section. Expression difference in this analysis might point at the strain-specific,

235 genotype-dependent mechanism underlying the phenotypic difference.

\section{Results}

$238 \quad$ Phenotypic analyses

239 CSA. Cross section analysis of soleus muscle fibers were done on mice of both sexes from 240 the $\mathrm{F}_{34}$ cohort. For muscle fiber cross-sectional area, we observed a statistically significant 241 sex by fiber type interaction $(P<0.0001)$. In the female $F_{34}$ mice there was no significant 242 difference between type I and type IIA muscle fiber areas (913 $\pm 229 \mu \mathrm{m}^{2}, \mathrm{n}=140$; and $952 \pm$ $243242 \mu \mathrm{m}^{2}, \mathrm{n}=140$ respectively; $\mathrm{P}=0.2$ ). However, there was a significant difference within the 244 males, with the type I muscle fiber area being smaller than IIA fiber area $\left(1084 \pm 238 \mu \mathrm{m}^{2}\right.$, 
$245 \mathrm{n}=187$; and $1215 \pm 294 \mu \mathrm{m}^{2}, \mathrm{n}=187$ respectively; $\left.\mathrm{P}<0.0001\right)$. Muscle fiber area was lower

246 in females than males for type I CSA, $(P<0.0001)$ and type IIA CSA $(P<0.0001)$.

247 Percentage of type I fibers. The number of type I fibers as a percentage of total fibers 248 varied substantially between individuals, ranging from $30 \%$ to $67 \%$ in females, and from $26 \%$ 249 to $59 \%$ in males (Figure 1) and was greater in females than males ( $46 \pm 8 \%, n=142$; and 39 $250 \pm 6 \%, n=189 ;$ respectively; $P<0.0001)$.

251 Total fiber number. No difference was observed in the total soleus fiber number between 252 females and males $(646 \pm 102, n=120$, and $667 \pm 105, n=177$, respectively; $P=0.0979)$.

\section{QTL analyses}

255

256

Muscle fiber traits approximated the normal distribution in both the $F_{2}$ and $F_{34}$ population (Supplementary Figure 1). We identified significant QTL (at the $1 \%$ or $5 \%$ level of genomewide statistical significance) (39) for CSA of type I and type IIA fibers and the percentage of type I fibers. We also identified chromosome-wide significant QTL for CSA of type I and type IIA fibers, the percentage of type I fibers and total fiber number (Table 1). The size of the support interval of these QTL ranged from $0.4-40.7 \mathrm{Mb}$, with a median of $4.6 \mathrm{Mb}$.

The QTL at the genome-wide level of significance for CSA of type I and type IIA fibers on chromosome 3 was named Mfq5. The QTL at the genome-wide level of significance for the percentage of type I fibers on chromosome 2 and 4 were named Mfq4 and Mfq6, respectively. The SM/J allele conferred a greater percentage of type I fibers at Mfq4, and a greater CSA at Mfq5. The LG/J allele conferred a greater percentage of type I fibers at Mfq6 locus.

A significant QTL affecting CSA of type I and type IIA fibers was also detected on chromosome 11 (Figure 2) within the same region as locus Mfq3, previously identified in the $F_{2}$ intercross of the same parental strains (11). The QTL exhibited male-specificity in both 
270 type I and IIA fibers of the $\mathrm{F}_{34}$ mice (Figure 3). Because this QTL recapitulated properties of

271 the Mfq3 locus, which we also found to be male specific in the $F_{2}$ population, we concluded

272 that the same locus has been refined in $\mathrm{F}_{34}$ and did not assign a new name for this $\mathrm{QTL}$.

273 Earlier reported Mfq2 locus has been refined in a similar manner; a QTL on chromosome 6

274 affecting CSA of type I and type IIA fibers (at 1\% chromosome specific threshold) was

275 engulfed by the support interval of $M f q 2$ and also replicated its increasing allele, LG/J, in

276 both females and males (not shown).

\section{Gene expression analyses}

278

279
We hypothesized that each identified QTL harbours one or more genetic variants that drive phenotypic differences by means of differential gene expression. Hypothesis driven analysis of differential expression in soleus muscle was performed between LG/J and SM/J strains for the genes in the most robust QTLs affecting fiber CSA or \% Type I fibers (Mfq3, Mfq4, Mfq5 and Mfq6). The Mouse Gene 2.0 ST expression array contains 159 genes residing within the support intervals of these QTLs (Supplementary Table 2). Twenty genes (Table 2) showed evidence of differential expression (ANOVA, p $\leq 0.05$ ), 2 of which, Alad and Hdhd3, were significant after correction for the multiple testing problem (Storey's FDR q $\leq 0.05$ ). Compared to other tissues and cell types, expression of differentially expressed genes Mafb, Acyp2 and Mtif2 (Table 2), is particularly enriched in skeletal muscle (BioGPS, Mouse MOE430 gene expression data).

\section{$\underline{\text { Genomic analyses }}$}

Positional candidates with non-synonymous polymorphisms provide a plausible genetic cause for the phenotypic differences. Based on the genomic sequence of the LG/J and SM/J strains (56), we identified 21 genes in the QTL regions with non-synonymous polymorphisms predicted to affect protein function by at least one out of three algorithms used in the analysis (Supplementary Table 3). Four of those genes (Mfq3: Mtif2, Rtn4, Psme4; Mfq5: Dnajc19) are prioritized further because of their preferential expression in 
muscle lineage (differentiated muscle and/or $\mathrm{C} 2 \mathrm{C} 12$ myoblasts) compared to other tissues

297 and cell types. Among those, the Mtif2 gene differs by 3 (rs26871496, rs26871494,

298 rs29436813) and Rtn4 by 9 (rs29473364, rs29469198, rs13463765, rs29465940,

299 rs26857726, rs26857725, rs29474377, rs26857722, rs26857721) amino acids between the

300 two strains. At all SNPs the SM/J strains carries reference while the LG/J strain the

301 alternative allele.

302 Candidate gene analyses

303 The Chd6 gene emerged as a differentially expressed positional candidate for the Mfq4

304 locus affecting percentage of type I fibers (Table 2). To test its effect we examined soleus

305 muscles of Chd6 knockout, heterozygous and wild type littermates. This analysis however

306 revealed that the genotype of the animals did not have a significant effect $(P=0.30)$ on the

307 percentage of type I fibers (Figure 4).

308 The Alad gene emerged as a candidate for another locus affecting proportion of type I fibers,

309 Mfq6. In the animals of an advanced intercross between the C57BL/6J and DBA/2J strains

310 (these strains carry one or three copies of Alad, respectively (3)), we examined if percentage

311 of type I fibers was genotype-dependent. The analysis revealed no difference in the

312 percentage of type I fibres between the carriers of the C57BL/6J and the DBA/2J alleles, 42

$313 \pm 7 \%$ and $42 \pm 8 \%$, respectively. 
A previous study on muscle weight in LG/J and SM/J strains identified a two-fold difference in soleus muscle size (47). We then explored the cellular and genetic mechanisms contributing to this phenomenon, finding that the difference was largely due to the CSA of muscle fibers and we mapped QTL affecting muscle fiber traits in an $F_{2}$ intercross between the $L G / J$ and SM/J strains (11). The present study, which utilizes the $F_{34}$ advanced intercross, verified, refined and expanded our earlier findings.

A number of studies have previously reported the effects of Stat5a and Stat5b (36), Pgc-1a (42), Ky (4), myostatin (54), leptin (61), calcineurin (76), Sod1 (5), alpha-actinin-3 (50), dystrophin (7), Tbx15 (41) and IIB myosin heavy chains (2) genes on muscle fiber area in knockout or mutant models. In addition, Pgc-1a (75), calcineurin (76), Foxo1 (34) and myostatin (20) are reported to affect the proportion of muscle fiber types. However, the genomic positions of these genes have not been linked to muscle fiber differences between the LG/J and SM/J strains, implicating involvement of novel genes.

Muscle fiber number. The number of fibers is an important determinant of muscle size and functional properties. It is set during embryogenesis and the first post-natal week in mice (78). The number of muscle fibers in males $(667 \pm 105)$ and females $(646 \pm 102)$ of the $F_{34}$ population was comparable to that observed in the soleus of the $F_{2}$ population (645 \pm 102 and $595 \pm 107$, respectively), and within the range of the fiber count observed in solei of a variety of different strains of mice $\sim 250-\sim 900$ fibers $(32,49,57,70,72)$.

From these data it emerged that males and females are born with a similar number of fibers in soleus muscle, and that the sex difference in muscle weight (males have approximately $30 \%$ larger soleus than females) is due to the difference in fiber size. Comparison of the parental strains also revealed a similar number of fibers (11), despite the 2-fold difference in soleus weight (47), demonstrating that size rather than number of fibers determines variation in muscle weight between the $L G / J$ and $S M / J$ strains. 
340 Fiber area. The CSA of muscle fibers in the LG/J strain is $49 \%$ to $90 \%$ greater than the 341 corresponding fibers in the SM/J strain, indicating that this variable accounts for a large 342 portion of the muscle mass difference between the strains (47).

343 The area of type I (1084 $\pm 238 \mu \mathrm{m}^{2}$ and $913 \pm 229 \mu \mathrm{m}^{2}$ for males and females, respectively $)$ 344 and type IIA (1215 $\pm 294 \mu \mathrm{m}^{2}$ and $952 \pm 242 \mu \mathrm{m}^{2}$, respectively) of the $F_{34}$ mice was 345 comparable to the corresponding fiber area of the $F_{2}$ mice of the same lineage (11) and it is 346 within the range reported for the type I, between $920 \mu \mathrm{m}^{2}$ and $1780 \mu \mathrm{m}^{2}(32,57,70)$, and 347 type IIA fiber area, between $700 \mu \mathrm{m}^{2}$ and $1400 \mu \mathrm{m}^{2}(32,70)$, in various inbred mouse 348 strains.

349 Percentage of type I fibers. The percentage of type I fibers in male ( $39 \pm 6 \%)$ and female $350(47 \pm 8 \%) F_{34}$ mice were also within the range of previous studies, which showed the 351 percentage of type I fibers in the soleus muscle fluctuates between $\sim 25$ and $\sim 66 \%(32,57$, 352 70).

353 In the $F_{34}$ mice we replicated our observation in the $F_{2}$ population that the percentage of type 354 I fibers was significantly greater in females than males. This sex difference is also observed 355 in various human muscles where, in general, women have a higher percentage of type I 356 muscle fibers than males $(27,53,60,64,67)$. The phenomenon is likely to be explained, at 357 least partly, by the effect of androgens; castration leads to a higher percentage of type I 358 fibers in the soleus of male mice (73).

Validation and refinement of genetic architecture. In the present study, we validated and refined the genetic architecture of muscle fibers identified in an $F_{2}$ intercross between the same parental strains (11). In order to increase QTL detection power, we increased sample size by combining the $\mathrm{F}_{34}$ and $\mathrm{F}_{2}$ data. The median mapping resolution of $4.6 \mathrm{Mb}$ for muscle fiber QTLs was comparable with 3.7 Mb of muscle weight QTLs obtained in the same population albeit using $\sim 1,600$ fewer genetic markers than in the present analysis (47). $\mathrm{A}$ genome-wide significant QTL identified in the present study between $27.9 \mathrm{Mb}$ and $31.4 \mathrm{Mb}$ 
on chromosome 11 (Table 1) overlapped with a significant QTL, Mfq3, mapped in the $F_{2}$ population (11). In addition to the chromosomal location, the increasing allele of this locus $(L G / J)$ and its male-specific effect (Figure 3) were also replicated in $F_{34}$, suggesting that the same gene(s) were involved in two different populations and permitting us to refine the Mfq3 locus from $51.6 \mathrm{Mb}$ to $3.57 \mathrm{Mb}$. The presence of two satellite QTL proximal of the refined Mfq3 (Table 1) suggests that the QTL observed in the $F_{2}$ population (11) might have been an outcome of up to three linked loci.

The recently reported "mini-muscle" locus, mapped to 67.1-70.2 Mb on chromosome 11, affects muscle fiber area and proportion of fiber types (21-23). However, the mutation responsible for the "mini-muscle" phenotype maps to an intron of Myh4 gene located at 67.2 $\mathrm{Mb}$ (31), between the support intervals of two adjacent QTLs affecting fiber type between the LG/J and SM/J strains (Table 1). Together, these data suggest that a number of genes residing on chromosome 11 might be involved in the regulation of muscle fiber phenotypes.

The QTL affecting the CSA of type I and type IIA fibers on chromosome 6, albeit at $1 \%$ chromosome-wide threshold of significance (Table 1), overlapped with the Mfq2 locus found in the $F_{2}$ population, characterized by the same increasing allele, LG/J. Thus, the support interval of Mfq2 could be considered to be $5.18 \mathrm{Mb}$ rather than the previously reported 56.5 Mb. Importantly, the immediate proximity of the refined region (Chr 6: 110.8-116.0 Mb) to the syntenic region (Chr 6:116.0-118.0 Mb) implicated in the QTL affecting the diameter of pig IIA fibers (17) suggest that the same genes could be underlying the effects of these QTLs in mice.

A QTL affecting percentage of type I fibers (at 10\% chromosome-wide threshold) on chromosome 1 (67.6to $70.8 \mathrm{Mb}$ ) overlapped with Mfq1 locus which influenced the CSA of type I and type IIA fiber area in the $F_{2}$ population (11). However, because the CSA and percentage of type I fibers are poorly correlated traits both in the $F_{34}$ (Supplementary Table 
391 4) and the $F_{2}$ mice (11), it is likely that different genes are underlying the Mfq1 locus and the

392 QTL identified in the $F_{34}$ population. Further studies are required to clarify this observation.

\section{Transcriptome analysis}

394 In the present study, the expressed transcriptome in soleus muscle of the parental strains

395 was examined in order to facilitate nomination of the candidate genes within the refined QTL. We hypothesized that if the phenotypic effect of the QTL was brought about by the allele specific abundance of transcripts encoded by genes within the QTL, such genes would be differentially expressed in the transcriptome between the parental strains. Comparison of expression of the genes within the four most robust QTLs identified Alad and Hdhd3 genes as potential candidates for the Mfq6 locus, which affects the proportion of type I fibers. Transcripts of both genes are more abundant in the LG/J compared to the SM/J strain. This is consistent with our findings in the TA muscle of the same strains (48). Of these two identified candidate genes, transcripts of Alad are $\sim 20$ times more abundant in the mouse muscle than Hdhd3, regardless of strain. In addition, Alad may play a role during myogenesis as its expression in $\mathrm{C} 2 \mathrm{C} 12$ myogenic cells is 5 -fold higher compared to differentiated muscle (79).

\section{Candidate genes.}

The support intervals of four most robust QTLs harbor 159 genes (Supplementary Table 2). These regions were scrutinized further for the genes fulfilling one of the following criteria: presence of the functional variants (i.e. non-synonymous SNPs predicted to alter function of encoded protein); abundance of transcript in muscle lineage, particularly in comparison to other tissues and cell types; differential expression in the soleus of the two strains; and by comparing genomic sequence between the LG/J and SM/J strains a list of 21 genes was highlighted (Supplementary Table 3) with the strain-specific functional variants. Using bioinformatics, 4 genes abundantly and/or preferentially expressed in skeletal muscle compared to other types of tissues and cells were identified. Our own analysis of gene 
expression in soleus muscle highlighted a set of 20 genes differentially expressed between

418 the two strains (Table 2). Intersection of all these lists permitted us to prioritise nine

419 candidate genes which appeared on more than one of these lists and/or for which

420 independent and accessible validation models were available (i.e. Chd6 and Alad). Because

421 neither the Chd6 (Figure 4) nor Alad genes were found to affect proportion of type I fibres in

422 the way predicted by the QTL analyses, the list of prioritised candidates was reduced to 7

423 genes annotated in Supplementary Table 5. Three out of four QTLs contain one (Mfq6) or

424 more candidate genes. All candidates are abundantly transcribed in muscle lineage with

425 Psme4, Acyp2 and Mafb showing the highest level of expression in skeletal muscle

426 compared to other tissues and cells. None of the seven candidates have been previously

427 implicated to affect properties of skeletal muscle fibres although some of them have been

428 implicated in cardiomyopathy or function as transcription factors (Supplementary Table 5).

429 Thus, genomic and gene expression analyses permitted focusing on a limited number of

430 positional candidates in the future validation studies for establishing the causative genes.

\section{Conclusion}

432 In conclusion, we have refined the genetic architecture affecting cross sectional area of

433 soleus muscle fibers and proportion of type I fibers in the LG/J and SM/J derived lineage.

434 Integrating QTL mapping, genomic and transcriptome data from homologous muscle

435 highlighted several candidate genes that may underpin muscle phenotypes critical to health

436 and disease and worthy of follow up analyses. 
442 The study was supported by NIH R01AR056280 grant (AL), NIH R01DA024845 (AAP) and

443 Marie Curie International Reintegration Grant $249156(A L)$.

444

445 Acknowledgements

446 The authors wish to acknowledge technical assistance from Diane Stewart, Jasmine C.

447 Berry and Jake T. Brown. We acknowledge the Dartmouth Mouse Modelling Shared

448 Resource of the Norris Cotton Cancer Center (support grant P30CA023108-27), for

449 providing Chd6 knockout mouse samples.

450

451 Author contributions

452 A.L. conceived and supervised the study, A.M.C. phenotyped muscle samples, A.A.P. 453 provided genotypes and oversaw the QTL analyses, R.C. designed the QTLRel software 454 used in the QTL analysis, A.M.C. carried out QTL mapping, M.E.S, C.M. and E.C.D. did 455 transcriptome analysis, S.N.F. and J.L.F. generated and provided Chd6 knockout samples, 456 A.L. and A.M.C. wrote the manuscript with input from all co-authors.

457 
460 Figure 1. Individual variability in proportion of oxidative fibers. Representative images 461 of $F_{34}$ female soleus cross-sections following myosin ATPase staining (acid pre-incubation).

462 Dark fibers type I, pale fibers type IIA.

Figure 2. Type I fiber cross-sectional area QTL on chromosome 11. Analyses were carried out in the $F_{2}$ intercross and in the combined $F_{2}$ and $F_{34}$ populations. $X$-axis indicates the relative position in the linkage map in centimorgan (cM). The thresholds are at the level of 0.05 genome wise significance for the $F_{2}$ output (dotted line) and combined output (solid

468 line).

Figure 3. Sex specificity of Mfq3 locus on cross-sectional area (CSA) of soleus type I 471 and IIA fibers in the $\mathbf{F}_{34}$ intercross. Mean and SEM. Genotype at the peak marker: LG, homozygous for LG/J allele; $\mathrm{H}$, heterozygous; SM, homozygous for SM/J allele.

Figure4. Percentage of type I fibers in the soleus muscle of 4 month old Chd6 knockout (KO), heterozygous (HET) and wild-type (WT) females. There is no difference in percentage of type I muscle fibers in the soleus muscle between knockout, heterozygotes and wild-type groups $(P=0.3041)$. Each data point is from a single mouse, horizontal lines 
481 Table 1. Characteristics of muscle fiber QTL in combined analyses of the $F_{2}$ and $F_{34}$ 482 intercrosses derived from the $L G / J$ and $S M / J$ strains.

\begin{tabular}{|c|c|c|c|c|c|c|c|}
\hline Chr & Thr ${ }^{* *}$ & Level $^{\star \star *}$ & Start $\mathbf{M b}^{\dagger}$ & End $\mathbf{M b}$ & Size $\mathbf{M b}$ & Trait & Locus $¥$ \\
\hline 1 & $C$ & 0.1 & 67.6 & 70.7 & 3.1 & \% Type I & \\
\hline 1 & C & 0.1 & 193.9 & 194.3 & 0.4 & $\%$ Type I \& CSA2A & \\
\hline 2 & C & 0.1 & 92.4 & 104.8 & 12.4 & \% Type I & \\
\hline 2 & C & 0.05 & 139.6 & 145.6 & 6.0 & \% Type I & \\
\hline 2 & G & 0.01 & 158.8 & 162.5 & 3.7 & \% Type I & Mfq4 (SM) \\
\hline 3 & G & 0.05 & 33.6 & 40.0 & 6.4 & CSA1 \& CSA2A & Mfq5 (SM) \\
\hline 4 & G & 0.05 & 57.7 & 62.7 & 5.0 & \% Type I & Mfq6 (LG) \\
\hline 4 & C & 0.05 & 103.9 & 106.1 & 2.2 & \% Type I & \\
\hline 6 & C & 0.05 & 81.9 & 84.1 & 2.2 & CSAIIA & \\
\hline 6 & C & 0.01 & 110.8 & 116.0 & 5.2 & CSA1 \& CSA2A & $M f q 2^{*}(L G)$ \\
\hline 7 & C & 0.05 & 138.4 & 140.0 & 1.6 & \% Type I & \\
\hline 8 & C & 0.1 & 7.4 & 12.4 & 5.0 & \% Type I & \\
\hline 8 & C & 0.05 & 89.0 & 92.4 & 3.4 & TOTAL & \\
\hline 8 & C & 0.01 & 121.9 & 128.6 & 6.7 & TOTAL & \\
\hline 10 & G & 0.1 & 120.7 & 121.3 & 0.6 & \% Type I & \\
\hline 11 & C & 0.1 & 12.4 & 17.2 & 4.8 & CSAlIA & \\
\hline 11 & C & 0.1 & 19.1 & 23.1 & 4.0 & CSAIIA & \\
\hline 11 & G & 0.01 & 28.0 & 31.5 & 3.5 & CSA1 \& CSA2A & $\operatorname{Mfq}^{*}(L G)$ \\
\hline 11 & C & 0.1 & 62.5 & 64.2 & 1.7 & \% Type I & \\
\hline 11 & C & 0.1 & 70.6 & 76.2 & 5.6 & \% Type I & \\
\hline 12 & C & 0.1 & 27.6 & 29.3 & 1.7 & CSA1 & \\
\hline 13 & C & 0.01 & 5.3 & 9.9 & 4.6 & \% Type I & \\
\hline 13 & C & 0.05 & 71.5 & 74.0 & 2.5 & CSAIIA & \\
\hline 14 & C & 0.05 & 93.6 & 102.3 & 8.7 & CSAIIA & \\
\hline 15 & C & 0.1 & 12.1 & 20.3 & 8.2 & TOTAL & \\
\hline 16 & C & 0.05 & 68.9 & 75.1 & 6.2 & CSA1 \& CSA2A & \\
\hline$x$ & C & 0.01 & 11.8 & 52.5 & 40.7 & TOTAL & \\
\hline \multicolumn{8}{|c|}{ * refined previously identified QTL in the LG/J and SM/J F $F_{2}$ intercross (47). } \\
\hline \multicolumn{8}{|c|}{${ }^{* *} \mathrm{C}$ - chromosome-wide threshold, G- genome-wide threshold } \\
\hline \multicolumn{8}{|c|}{ *** Level of significance } \\
\hline \multicolumn{8}{|c|}{$¥ \mathrm{LG}$-increasing allele is $\mathrm{LG} / \mathrm{J}, \mathrm{SM}$ - increasing allele is $\mathrm{SM} / \mathrm{J}$} \\
\hline \multicolumn{8}{|c|}{${ }^{\dagger}$ Genomic positions based on GRCm38.p3. } \\
\hline
\end{tabular}


Table 2. Positional candidate genes differentially expressed between $L G / J$ and $S M / J$ soleus muscles.

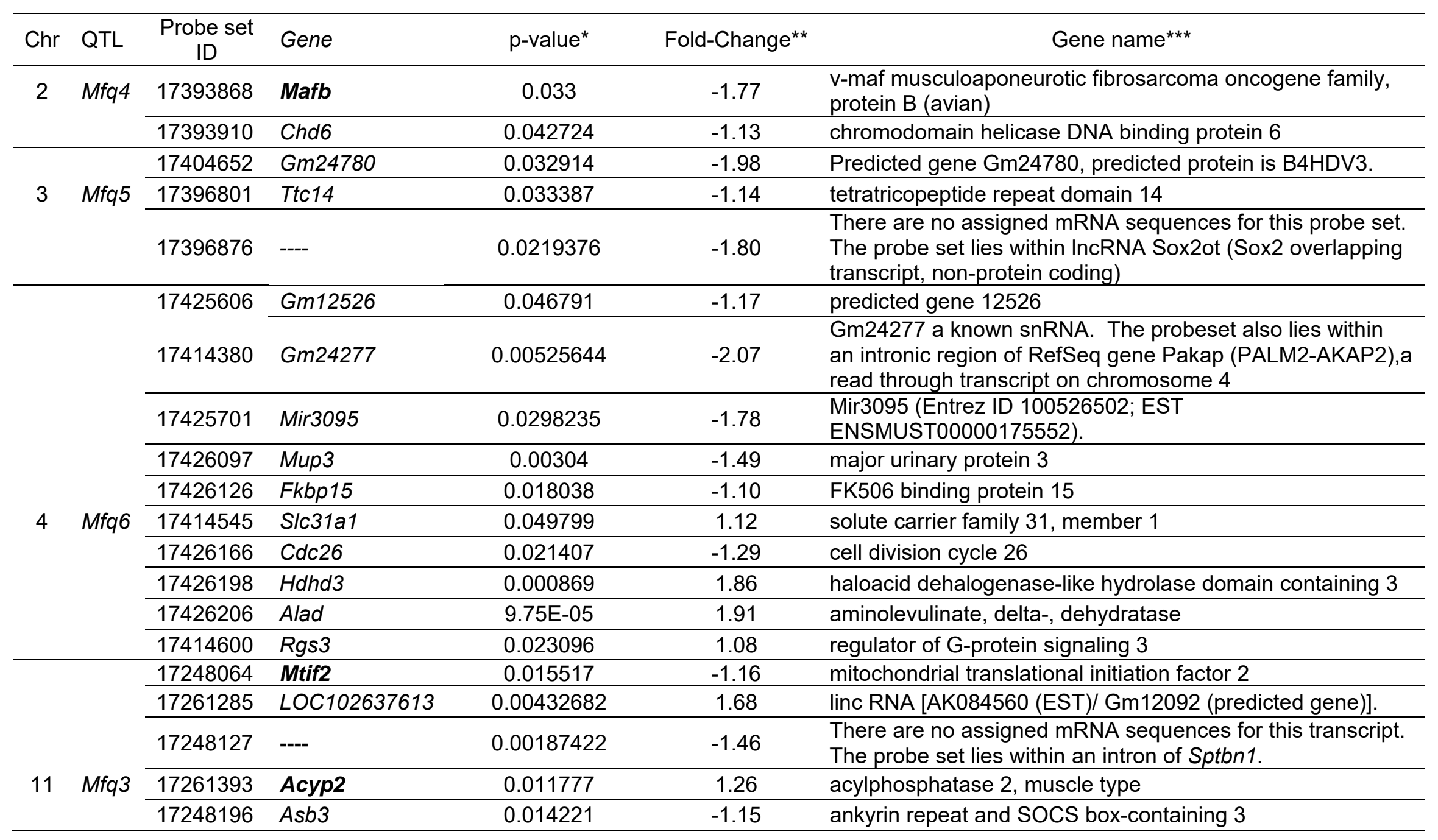


* ANOVA p-value for strain effect; ** Fold change uses SM/J as baseline (negative values indicate LG/J expression is down compared to SM/J, positive values $\mathrm{LG} / \mathrm{J}$ expression up compared to $\mathrm{SM} / \mathrm{J}$ ); bold indicates that gene is predominantly and/ or strongly expressed in skeletal muscle tissue (79). ${ }^{* * *}$ For probe sets not designed against an annotated gene, genes at the genomic loci of the Affymetrix probeset were identified in UCSC genome browser using mouse genome build GRCm38. 
498 1. Abe T, Saburi J, Hasebe H, Nakagawa T, Kawamura T, Saito K, Nade T, Misumi S, Okumura 499 T, Kuchida K, Hayashi T, Nakane S, Mitsuhasi T, Nirasawa K, Sugimoto Y, and Kobayashi E. Bovine 500 quantitative trait loci analysis for growth, carcass, and meat quality traits in an F2 population from a 501 cross between Japanese Black and Limousin. Journal of animal science 86: 2821-2832, 2008.

502 2. Allen DL, Sartorius CA, Sycuro LK, and Leinwand LA. Different pathways regulate expression 503 of the skeletal myosin heavy chain genes. The Journal of biological chemistry 276: 43524-43533, 5042001.

505 3. Bishop TR, Miller MW, Wang A, and Dierks PM. Multiple copies of the ALA-D gene are 506 located at the Lv locus in Mus domesticus mice. Genomics 48: 221-231, 1998.

507 4. Blanco G, Coulton GR, Biggin A, Grainge C, Moss J, Barrett M, Berquin A, Marechal G, 508 Skynner M, van Mier P, Nikitopoulou A, Kraus M, Ponting CP, Mason RM, and Brown SD. The 509 kyphoscoliosis (ky) mouse is deficient in hypertrophic responses and is caused by a mutation in a novel muscle-specific protein. Human molecular genetics 10: 9-16, 2001.

5. Bordet T, Schmalbruch H, Pettmann B, Hagege A, Castelnau-Ptakhine L, Kahn A, and Haase G. Adenoviral cardiotrophin-1 gene transfer protects pmn mice from progressive motor neuronopathy. The Journal of clinical investigation 104: 1077-1085, 1999.

6. Bottinelli R, and Reggiani C. Human skeletal muscle fibres: molecular and functional diversity. Progress in biophysics and molecular biology 73: 195-262, 2000.

7. Briguet A, Courdier-Fruh I, Foster M, Meier T, and Magyar JP. Histological parameters for the quantitative assessment of muscular dystrophy in the $\mathrm{mdx}$-mouse. Neuromuscular disorders : NMD 14: 675-682, 2004.

8. Brooke $\mathbf{M H}$, and Kaiser KK. Muscle fiber types: how many and what kind? Archives of neurology 23: 369-379, 1970.

9. Carbonetto P, Cheng R, Gyekis JP, Parker CC, Blizard DA, Palmer AA, and Lionikas A. Discovery and refinement of muscle weight QTLs in B6 $\times$ D2 advanced intercross mice. Physiological Genomics 46: 571-582, 2014.

10. Carpenter CE, Rice OD, Cockett NE, and Snowder GD. Histology and composition of muscles from normal and callipyge lambs. Journal of animal science 74: 388-393, 1996.

11. Carroll AM, Palmer AA, and Lionikas A. QTL Analysis of Type I and Type IIA Fibers in Soleus Muscle in a Cross between LG/J and SM/J Mouse Strains. Frontiers in genetics 2: 99, 2011.

12. Cheng $R$, Abney $M$, Palmer AA, and Skol AD. QTLRel: an $R$ package for genome-wide association studies in which relatedness is a concern. BMC genetics 12: 66, 2011.

13. Cheng R, Lim JE, Samocha KE, Sokoloff G, Abney M, Skol AD, and Palmer AA. Genome-wide association studies and the problem of relatedness among advanced intercross lines and other highly recombinant populations. Genetics 185: 1033-1044, 2010.

14. Cheng R, and Palmer AA. A Simulation Study of Permutation, Bootstrap, and Gene Dropping for Assessing Statistical Significance in the Case of Unequal Relatedness. Genetics 193: 1015-1018, 2013.

15. Costill DL, Daniels J, Evans W, Fink W, Krahenbuhl G, and Saltin B. Skeletal muscle enzymes and fiber composition in male and female track athletes. Journal of applied physiology 40: 149-154, 1976.

16. Darvasi A, and Soller M. Advanced intercross lines, an experimental population for fine genetic mapping. Genetics 141: 1199-1207, 1995.

17. Estelle J, Gil F, Vazquez JM, Latorre R, Ramirez G, Barragan MC, Folch JM, Noguera JL, Toro MA, and Perez-Enciso M. A quantitative trait locus genome scan for porcine muscle fiber traits reveals overdominance and epistasis. Journal of animal science 86: 3290-3299, 2008. 
544 18. Fink WJ, Costill DL, and Pollock ML. Submaximal and maximal working capacity of elite 545 distance runners. Part II. Muscle fiber composition and enzyme activities. Annals of the New York 546 Academy of Sciences 301: 323-327, 1977.

547 19. Frederiksen H, Gaist D, Petersen HC, Hjelmborg J, McGue M, Vaupel JW, and Christensen K. 548 Hand grip strength: a phenotype suitable for identifying genetic variants affecting mid- and late-life 549 physical functioning. Genetic epidemiology 23: 110-122, 2002.

$55020 . \quad$ Girgenrath S, Song K, and Whittemore LA. Loss of myostatin expression alters fiber-type 551 distribution and expression of myosin heavy chain isoforms in slow- and fast-type skeletal muscle. 552 Muscle \& nerve 31: 34-40, 2005.

553 21. Guderley H, Houle-Leroy P, Diffee GM, Camp DM, and Garland T, Jr. Morphometry, 554 ultrastructure, myosin isoforms, and metabolic capacities of the "mini muscles" favoured by 555 selection for high activity in house mice. Comparative biochemistry and physiology Part B, 556 Biochemistry \& molecular biology 144: 271-282, 2006.

557 22. Guderley H, Joanisse DR, Mokas S, Bilodeau GM, and Garland T, Jr. Altered fibre types in 558 gastrocnemius muscle of high wheel-running selected mice with mini-muscle phenotypes.

559 Comparative biochemistry and physiology Part B, Biochemistry \& molecular biology 149: 490-500, 5602008.

561 23. Hartmann J, Garland T, Jr., Hannon RM, Kelly SA, Munoz G, and Pomp D. Fine mapping of 562 "mini-muscle," a recessive mutation causing reduced hindlimb muscle mass in mice. The Journal of 563 heredity 99: 679-687, 2008.

56424 . Hernelahti M, Tikkanen HO, Karjalainen J, and Kujala UM. Muscle fiber-type distribution as 565 a predictor of blood pressure: a 19-year follow-up study. Hypertension 45: 1019-1023, 2005.

$56625 . \quad$ Hubal MJ, Gordish-Dressman H, Thompson PD, Price TB, Hoffman EP, Angelopoulos TJ, 567 Gordon PM, Moyna NM, Pescatello LS, Visich PS, Zoeller RF, Seip RL, and Clarkson PM. Variability in 568 muscle size and strength gain after unilateral resistance training. Medicine and science in sports and 569 exercise 37: 964-972, 2005.

570 26. Huygens W, Thomis MA, Peeters MW, Vlietinck RF, and Beunen GP. Determinants and upper-limit heritabilities of skeletal muscle mass and strength. Canadian journal of applied physiology = Revue canadienne de physiologie appliquee 29: 186-200, 2004.

27. Jaworowski A, Porter MM, Holmback AM, Downham D, and Lexell J. Enzyme activities in the tibialis anterior muscle of young moderately active men and women: relationship with body composition, muscle cross-sectional area and fibre type composition. Acta physiologica Scandinavica 176: 215-225, 2002.

28. Kadi F, Eriksson A, Holmner S, Butler-Browne GS, and Thornell LE. Cellular adaptation of the trapezius muscle in strength-trained athletes. Histochemistry and cell biology 111: 189-195, 1999.

29. Karjalainen J, Tikkanen $\mathbf{H}$, Hernelahti $\mathbf{M}$, and Kujala UM. Muscle fiber-type distribution predicts weight gain and unfavorable left ventricular geometry: a 19 year follow-up study. BMC cardiovascular disorders 6: 2, 2006.

30. Karp CL, Grupe A, Schadt E, Ewart SL, Keane-Moore M, Cuomo PJ, KohI J, WahI L, Kuperman D, Germer S, Aud D, Peltz G, and Wills-Karp M. Identification of complement factor 5 as a susceptibility locus for experimental allergic asthma. Nature immunology 1: 221-226, 2000.

31. Kelly SA, Bell TA, Selitsky SR, Buus RJ, Hua K, Weinstock GM, Garland T, Pardo-Manuel de Villena F, and Pomp D. A Novel Intronic Single Nucleotide Polymorphism in the Myosin heavy polypeptide 4 Gene Is Responsible for the Mini-Muscle Phenotype Characterized by Major Reduction in Hind-Limb Muscle Mass in Mice. Genetics 195: 1385-1395, 2013.

32. Kilikevicius A, Venckunas T, Zelniene R, Carroll AM, Lionikaite S, Ratkevicius A, and Lionikas A. Divergent physiological characteristics and responses to endurance training among inbred mouse strains. Scandinavian journal of medicine \& science in sports 23: 657-668, 2013. 33. Kim J, Wang Z, Heymsfield SB, Baumgartner RN, and Gallagher D. Total-body skeletal muscle mass: estimation by a new dual-energy X-ray absorptiometry method. The American journal of clinical nutrition 76: 378-383, 2002. 

Kitajewski J, and Accili D. A Foxo/Notch pathway controls myogenic differentiation and fiber type specification. The Journal of clinical investigation 117: 2477-2485, 2007.

$598 \quad 35 . \quad$ Klein RF, Allard J, Avnur Z, Nikolcheva T, Rotstein D, Carlos AS, Shea M, Waters RV, 599 Belknap JK, Peltz G, and Orwoll ES. Regulation of bone mass in mice by the lipoxygenase gene 600 Alox15. Science (New York, NY) 303: 229-232, 2004.

601 36. Klover P, Chen W, Zhu BM, and Hennighausen L. Skeletal muscle growth and fiber 602 composition in mice are regulated through the transcription factors STAT5a/b: linking growth 603 hormone to the androgen receptor. FASEB journal : official publication of the Federation of American 604 Societies for Experimental Biology 23: 3140-3148, 2009.

605 37. Komi PV, Viitasalo JH, Havu M, Thorstensson A, Sjodin B, and Karlsson J. Skeletal muscle 606 fibres and muscle enzyme activities in monozygous and dizygous twins of both sexes. Acta 607 physiologica Scandinavica 100: 385-392, 1977.

608 38. Koohmaraie M, Shackelford SD, Wheeler TL, Lonergan SM, and Doumit ME. A muscle 609 hypertrophy condition in lamb (callipyge): characterization of effects on muscle growth and meat quality traits. Journal of animal science 73: 3596-3607, 1995.

39. Lander E, and Kruglyak L. Genetic dissection of complex traits: guidelines for interpreting and reporting linkage results. Nature genetics 11: 241-247, 1995.

40. Lathrop MJ, Chakrabarti L, Eng J, Harker Rhodes C, Lutz T, Nieto A, Denny Liggitt H, Warner S, Fields J, Stöger R, and Fiering S. Deletion of the Chd6 exon 12 affects motor coordination. Mammalian Genome 21: 130-142, 2010.

41. Lee KY, Singh MK, Ussar S, Wetzel P, Hirshman MF, Goodyear $\sqcup$, Kispert A, and Kahn CR. Tbx15 controls skeletal muscle fibre-type determination and muscle metabolism. Nature communications 6: 8054, 2015.

42. Leick L, Hellsten Y, Fentz J, Lyngby SS, Wojtaszewski JF, Hidalgo J, and Pilegaard H. PGC1alpha mediates exercise-induced skeletal muscle VEGF expression in mice. American journal of physiology Endocrinology and metabolism 297: E92-103, 2009.

43. Li WB, Ren J, Zhu WC, Guo BL, Yang B, Liu LT, Ding NS, Ma JW, Li L, and Huang LS. Mapping QTL for porcine muscle fibre traits in a White Duroc $x$ Erhualian $\mathrm{F}(2)$ resource population. Journal of animal breeding and genetics = Zeitschrift fur Tierzuchtung und Zuchtungsbiologie 126: 468-474, 2009.

44. Lillioja S, Young AA, Culter CL, Ivy JL, Abbott WG, Zawadzki JK, Yki-Jarvinen H, Christin L, Secomb TW, and Bogardus C. Skeletal muscle capillary density and fiber type are possible determinants of in vivo insulin resistance in man. The Journal of clinical investigation 80: 415-424, 1987.

45. Lionikas A, Blizard DA, Gerhard GS, Vandenbergh DJ, Stout JT, Vogler GP, McClearn GE, and Larsson L. Genetic determinants of weight of fast- and slow-twitch skeletal muscle in 500-day-old mice of the C57BL/6J and DBA/2J lineage. Physiological genomics 21: 184-192, 2005.

46. Lionikas A, Blizard DA, Vandenbergh DJ, Glover MG, Stout JT, Vogler GP, McClearn GE, and Larsson L. Genetic architecture of fast- and slow-twitch skeletal muscle weight in 200-day-old mice of the C57BL/6J and DBA/2J lineage. Physiological genomics 16: 141-152, 2003.

47. Lionikas A, Cheng R, Lim JE, Palmer AA, and Blizard DA. Fine-mapping of muscle weight QTL in LG/J and SM/J intercrosses. Physiological genomics 42a: 33-38, 2010.

48. Lionikas A, Meharg C, Derry JM, Ratkevicius A, Carroll AM, Vandenbergh DJ, and Blizard DA. Resolving candidate genes of mouse skeletal muscle QTL via RNA-Seq and expression network analyses. BMC genomics 13: 592, 2012.

49. Luff AR, and Goldspink G. Total number of fibers in muscles of several strains of mice. Journal of animal science 30: 891-893, 1970.

50. MacArthur DG, Seto JT, Chan S, Quinlan KG, Raftery JM, Turner N, Nicholson MD, Kee AJ, Hardeman EC, Gunning PW, Cooney GJ, Head SI, Yang N, and North KN. An Actn3 knockout mouse 
645 provides mechanistic insights into the association between alpha-actinin-3 deficiency and human 646 athletic performance. Human molecular genetics 17: 1076-1086, 2008.

647 51. MacDougall JD, Sale DG, Alway SE, and Sutton JR. Muscle fiber number in biceps brachii in 648 bodybuilders and control subjects. Journal of applied physiology: respiratory, environmental and 649 exercise physiology 57: 1399-1403, 1984.

$650 \quad 52 . \quad$ Malek M, Dekkers JC, Lee HK, Baas TJ, Prusa K, Huff-Lonergan E, and Rothschild MF. A

651 molecular genome scan analysis to identify chromosomal regions influencing economic traits in the 652 pig. II. Meat and muscle composition. Mammalian genome : official journal of the International 653 Mammalian Genome Society 12: 637-645, 2001.

654 53. Mannion AF, Dumas GA, Cooper RG, Espinosa FJ, Faris MW, and Stevenson JM. Muscle

655 fibre size and type distribution in thoracic and lumbar regions of erector spinae in healthy subjects

656 without low back pain: normal values and sex differences. Journal of anatomy 190 (Pt 4): 505-513,

6571997.

658 54. McPherron AC, Lawler AM, and Lee SJ. Regulation of skeletal muscle mass in mice by a new 659 TGF-beta superfamily member. Nature 387: 83-90, 1997.

$660 \quad 55 . \quad$ Nii M, Hayashi T, Mikawa S, Tani F, Niki A, Mori N, Uchida Y, Fujishima-Kanaya N, Komatsu 661 M, and Awata T. Quantitative trait loci mapping for meat quality and muscle fiber traits in a 662 Japanese wild boar x Large White intercross. Journal of animal science 83: 308-315, 2005.

663 56. Nikolskiy I, Conrad DF, Chun S, Fay JC, Cheverud JM, and Lawson HA. Using whole-genome 664 sequences of the LG/J and SM/J inbred mouse strains to prioritize quantitative trait genes and 665 nucleotides. BMC genomics 16: 415, 2015.

$66657 . \quad$ Nimmo MA, Wilson RH, and Snow DH. The inheritance of skeletal muscle fibre composition 667 in mice. Comparative biochemistry and physiology A, Comparative physiology 81: 109-115, 1985.

668 58. Pourhassan M, Bosy-Westphal A, Schautz B, Braun W, Gluer CC, and Muller MJ. Impact of 669 body composition during weight change on resting energy expenditure and homeostasis model 670 assessment index in overweight nonsmoking adults. The American journal of clinical nutrition 99: $671779-791,2014$.

672 59. Rehfeldt C, Ott G, Gerrard DE, Varga L, Schlote W, Williams JL, Renne U, and Bunger L.

673 Effects of the compact mutant myostatin allele Mstn (Cmpt-dl1Abc) introgressed into a high growth mouse line on skeletal muscle cellularity. Journal of muscle research and cell motility 26: 103-112, 2005.

60. Roepstorff C, Donsmark M, Thiele M, Vistisen B, Stewart G, Vissing K, Schjerling P, Hardie DG, Galbo H, and Kiens B. Sex differences in hormone-sensitive lipase expression, activity, and phosphorylation in skeletal muscle at rest and during exercise. American journal of physiology Endocrinology and metabolism 291: E1106-1114, 2006.

61. Sainz N, Rodriguez A, Catalan V, Becerril S, Ramirez B, Gomez-Ambrosi J, and Fruhbeck G. Leptin administration favors muscle mass accretion by decreasing FoxO3a and increasing PGC-1alpha in ob/ob mice. PloS one 4: e6808, 2009.

62. Schiaffino S. Fibre types in skeletal muscle: a personal account. Acta physiologica (Oxford, England) 199: 451-463, 2010.

63. Simoneau JA, and Bouchard C. Genetic determinism of fiber type proportion in human skeletal muscle. FASEB journal : official publication of the Federation of American Societies for Experimental Biology 9: 1091-1095, 1995.

64. Simoneau JA, and Bouchard C. Human variation in skeletal muscle fiber-type proportion and enzyme activities. The American journal of physiology 257: E567-572, 1989.

65. Sosnicki A. Histopathological observation of stress myopathy in M. longissimus in the pig and relationships with meat quality, fattening and slaughter traits. Journal of animal science 65: 584596, 1987.

66. Srikanthan P, and Karlamangla AS. Muscle Mass Index As a Predictor of Longevity in Older Adults. The American Journal of Medicine 127: 547-553, 2014. 

Fiber type composition of the vastus lateralis muscle of young men and women. The journal of histochemistry and cytochemistry : official journal of the Histochemistry Society 48: 623-629, 2000.

698 68. Stavaux D, Art T, McEntee K, Reznick M, and Lekeux P. Muscle fibre type and size, and 699 muscle capillary density in young double-muscled blue Belgian cattle. Zentralblatt fur 700 Veterinarmedizin Reihe A 41: 229-236, 1994.

701 69. Timson BF, Bowlin BK, Dudenhoeffer GA, and George JB. Fiber number, area, and composition of mouse soleus muscle following enlargement. Journal of applied physiology (Bethesda, Md : 1985) 58: 619-624, 1985.

70. Totsuka Y, Nagao Y, Horii T, Yonekawa H, Imai H, Hatta H, Izaike Y, Tokunaga T, and Atomi Y. Physical performance and soleus muscle fiber composition in wild-derived and laboratory inbred mouse strains. Journal of applied physiology (Bethesda, Md : 1985) 95: 720-727, 2003.

71. Van den Maagdenberg K, Stinckens A, Lefaucheur L, Buys N, and De Smet S. The effect of mutations in the insulin-like growth factor-II and ryanodine receptor-1 genes on biochemical and histochemical muscle fibre characteristics in pigs. Meat science 79: 757-766, 2008.

72. van der Laarse WJ, Diegenbach PC, and Maslam S. Quantitative histochemistry of three mouse hind-limb muscles: the relationship between calcium-stimulated myofibrillar ATPase and succinate dehydrogenase activities. The Histochemical journal 16: 529-541, 1984.

73. Vaughan HS, Aziz U, Goldspink G, and Nowell NW. Sex and stock differences in the histochemical myofibrillar adenosine triphosphatase reaction in the soleus muscle of the mouse. The journal of histochemistry and cytochemistry : official journal of the Histochemistry Society 22: 155159, 1974.

74. Wade AJ, Marbut MM, and Round JM. Muscle fibre type and aetiology of obesity. Lancet 335: 805-808, 1990.

75. Wang YX, Zhang CL, Yu RT, Cho HK, Nelson MC, Bayuga-Ocampo CR, Ham J, Kang H, and Evans RM. Regulation of muscle fiber type and running endurance by PPARdelta. PLoS biology 2: e294, 2004.

76. Wilkins BJ, Dai YS, Bueno OF, Parsons SA, Xu J, Plank DM, Jones F, Kimball TR, and Molkentin JD. Calcineurin/NFAT coupling participates in pathological, but not physiological, cardiac hypertrophy. Circulation research 94: 110-118, 2004.

77. Wimmers K, Fiedler I, Hardge T, Murani E, Schellander K, and Ponsuksili S. QTL for microstructural and biophysical muscle properties and body composition in pigs. BMC genetics 7: 15, 2006.

78. Wirtz P, Loermans HM, Peer PG, and Reintjes AG. Postnatal growth and differentiation of muscle fibres in the mouse. I. A histochemical and morphometrical investigation of normal muscle. Journal of anatomy 137 (Pt 1): 109-126, 1983.

79. Wu C, Orozco C, Boyer J, Leglise M, Goodale J, Batalov S, Hodge CL, Haase J, Janes J, Huss JW, 3rd, and Su Al. BioGPS: an extensible and customizable portal for querying and organizing gene annotation resources. Genome biology 10: R130, 2009.

80. Zhang Y, Xu P, Lu C, Kuang Y, Zhang X, Cao D, Li C, Chang Y, Hou N, Li H, Wang S, and Sun X. Genetic linkage mapping and analysis of muscle fiber-related QTLs in common carp (Cyprinus carpio L.). Marine biotechnology (New York, NY) 13: 376-392, 2011. 
A
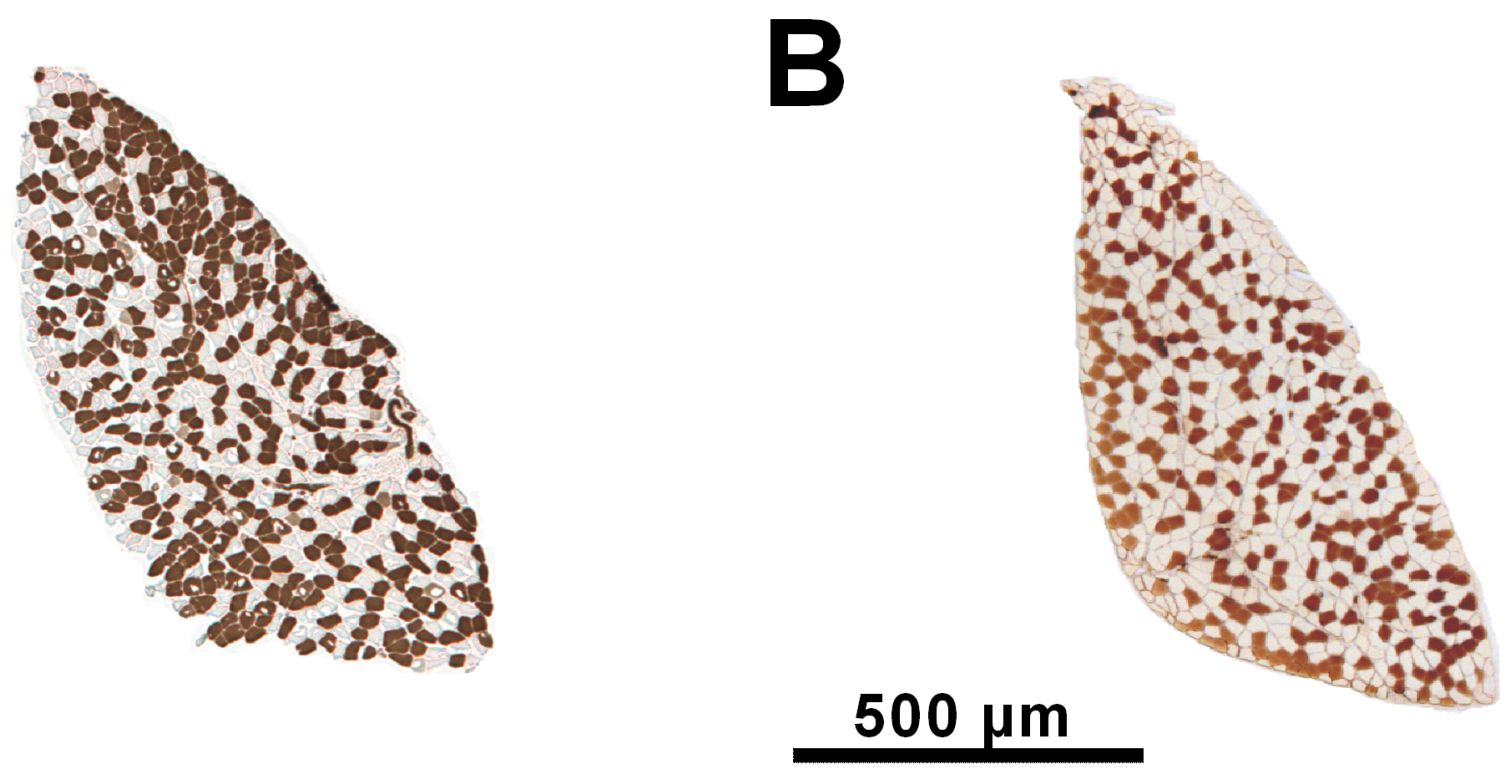
Chromosome 11

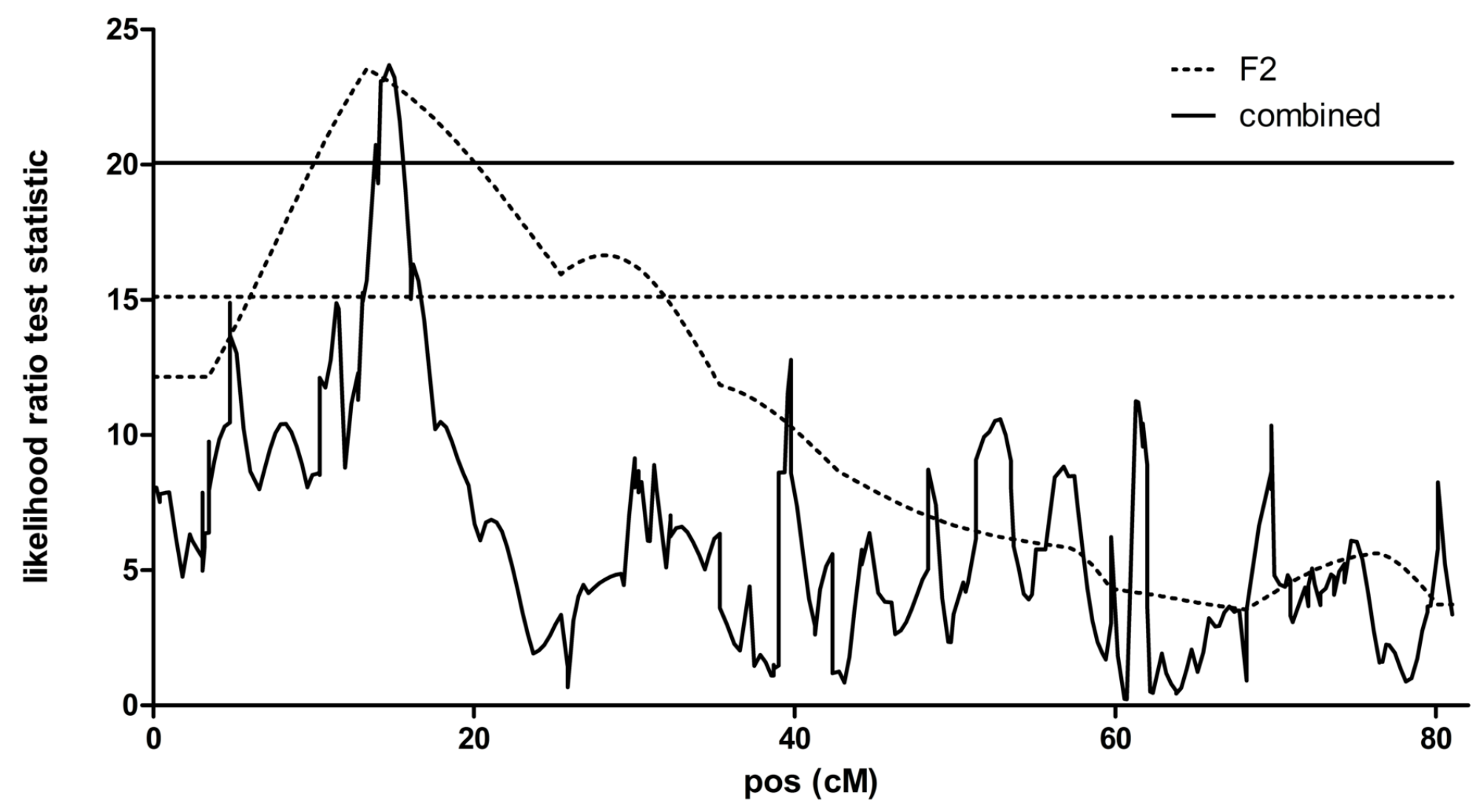




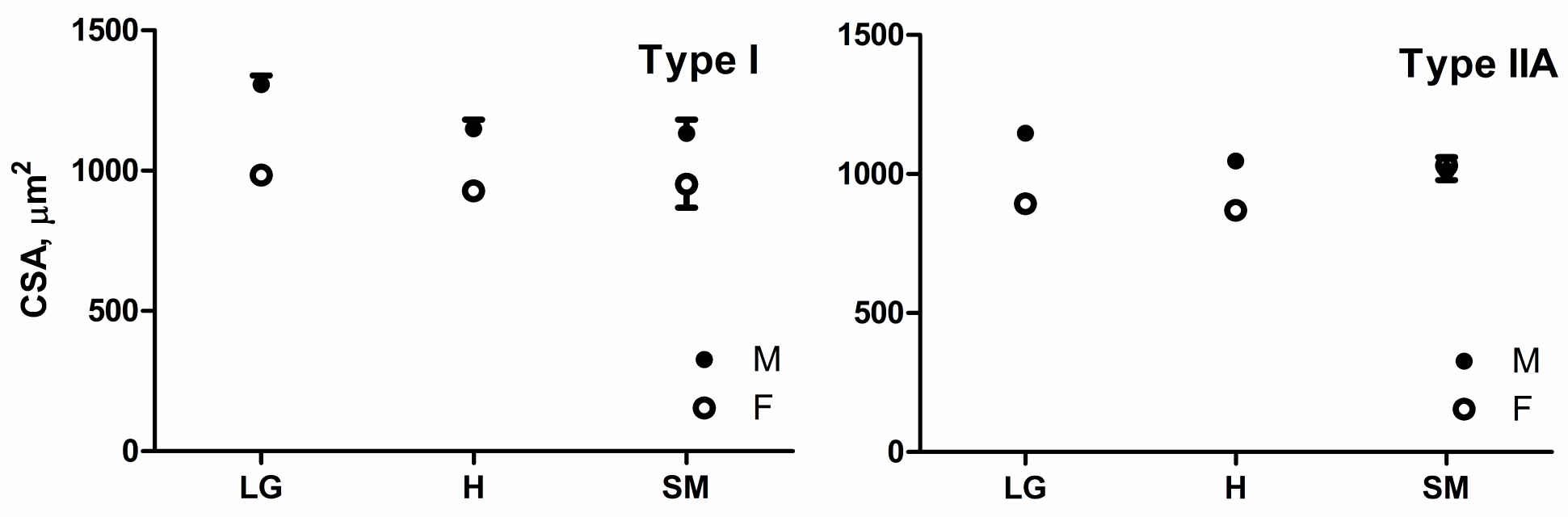




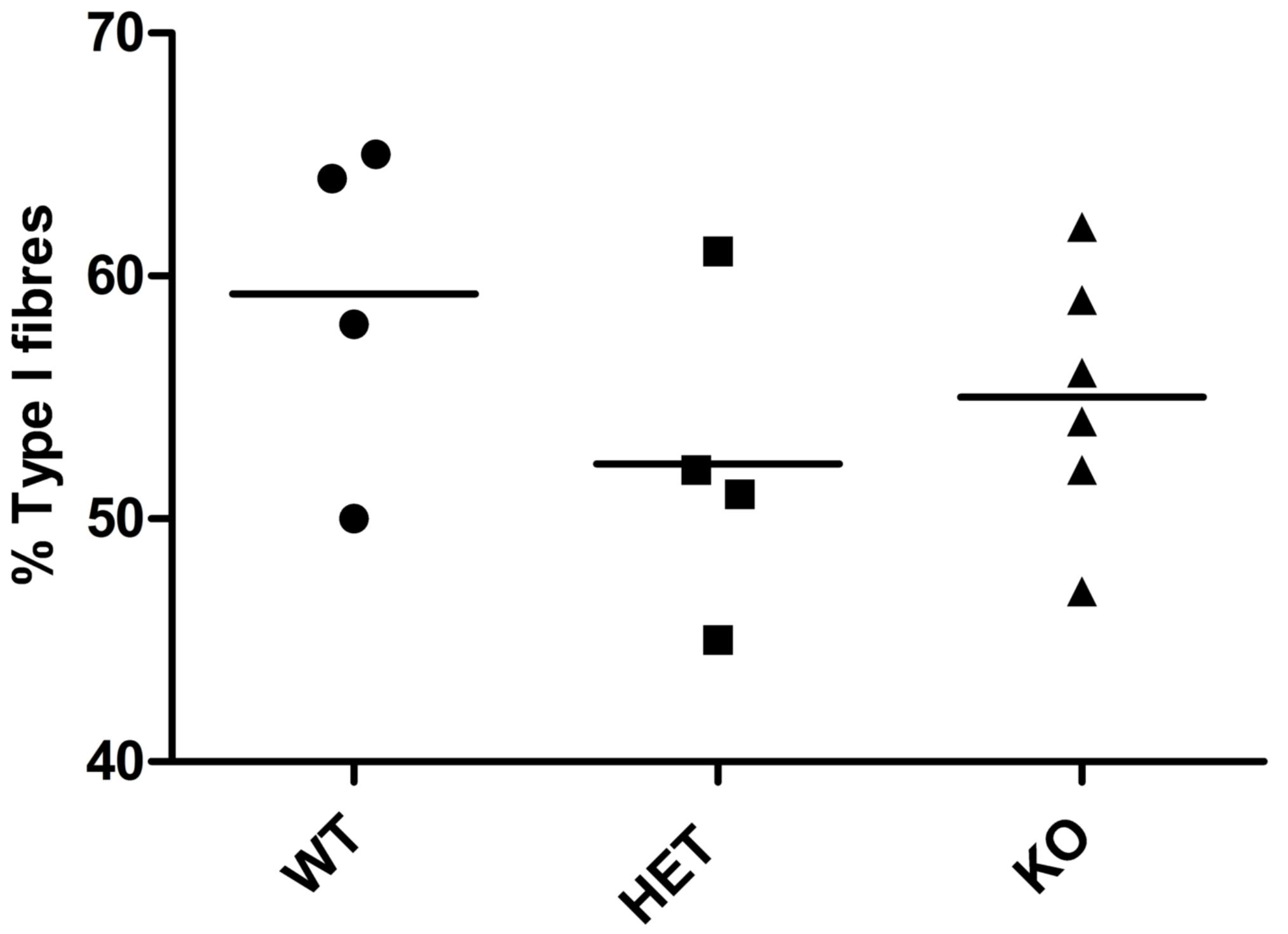

